\title{
Familias em litígio e o princípio do melhor interesse da criança na disputa de guarda
}

\author{
Josimar Antônio de Alcântara Mendes \\ Julia Sursis Nobre Ferro Bucher-Maluschke
}

\section{RESUMO}

Nas situações de separação parental envolvendo filhos, a Justiça frequentemente é chamada para decidir, entre outras coisas, a guarda das crianças/adolescentes. Neste sentido, este artigo objetivou compreender as concepções e práticas de atores jurídicos (juízes, promotores, psicólogos, assistentes sociais) que atuam nos casos de disputa de guarda a respeito do Princípio do Melhor Interesse da Criança. A metodologia foi qualitativa, descritiva e exploratória. Como instrumento, utilizou-se a entrevista semiestruturada. A análise deu-se por meio da formação das Zonas de Sentido, propostas por González Rey. Entrevistou-se um juiz, um promotor, um psicólogo e um assistente social que atuavam em casos de disputa de guarda em uma cidade satélite do Distrito Federal, por pelo menos cinco anos. Os resultados sugerem uma compreensão complexa do Princípio do Melhor Interesse da Criança e a sua dimensão Jurídico-Psicossocial. Observou-se também que as relações familiares e as dinâmicas do sistema familiar podem interferir no processo de guarda e dificultar e/ou facilitar a avaliação/atuação psicossocial e jurídica, impactando na garantia dos melhores interesses da criança.

Palavras-chave: Princípio do Melhor Interesse da Criança; Custódia da Criança; Divórcio; Vara de Família; Psicologia Forense.

\section{ABSTRACT}

\section{Litigating Families and the Principle of the best interests of the Child}

During the parental separation, sometimes the Judiciary is involved in this process to make a decision regarding the children's custody. Therefore, this work aimed to investigate the conceptions and practices of legal actors (judges, prosecutors, psychologists, social workers) regarding their practice within custody dispute cases and the principle of The Best Interests of the Child. The research design was guided by a qualitative, descriptive and exploratory approach through semi-structured interviews. The participants were a judge, a prosecutor, a psychologist and a social worker which had at least five-years of practice within custody dispute cases, placed in a city of Distrito Federal, Brazil. The analysis was based on the Sense Zones, proposed by González Rey. The results suggested a complex understanding ofn this principle and its legal-psychosocial dimension, as well as of its relation with the family relationships, which sometimes can affect and/or interfere in the custody process and hamper the evaluation and promotion of the child's best interests.

Keywords: Child's Best Interests; Custody Dispute; Divorce; Family Court; Forensic Psychology.

A discussão e aplicação do Princípio do Melhor Interesse da Criança/Adolescente (PMICA) é um tema recorrente na produção acadêmica psico-jurídica, sendo associado à adoção homoafetiva (Balestero \& Bahia, 2011), à guarda compartilhada (Petersen \& Carvalho, 2011), ao abuso sexual infantil (Seger \& Steinmetz, 2015), entre outros. Um contexto no qual frequentemente esse princípio é abordado é na vara de família

As rotinas e as práticas das Varas de Família são constantemente influenciadas por questões que envolvem o bem-estar físico e mental de crianças e adolescentes. Por isso, as ações dos operadores do Direito e dos profissionais forenses que trabalham com as famílias e

\section{Sobre os Autores}

J. A. de A. M. orcid.org/0000-0001-8230-1998 University of Sussex, Inglaterra josimards@gmail.com

J. S. N. F. B-M. orcid.org/0000-0002-9194-8993 Centro Universitário UniCEUBBrasília- DF psibucher@gmail.com

\section{Direitos Autorais}

Este é um artigo de acesso aberto e pode ser reproduzido livremente, distribuído,

transmitido ou modificado, por qualquer pessoa desde que usado sem fins comerciais. 0 trabalho é disponibilizado sob a licença Creative Commons CCBY-NC.

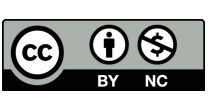




\section{W'INTERACÃO EM PSICOLOGIA}

suas crianças devem guiar-se pelo prisma do "melhor interesse da criança", visando priorizar e salvaguardar o bemestar físico e emocional dessas crianças e adolescentes. Contudo, nem sempre a criança foi vista como prioridade e nem pelo prisma dos seus interesses.

As noções de 'criança' e 'infância' são construções socioculturais modernas. Até antes do século XVII, as crianças não tinham um lugar claro nas relações sociais. Elas eram vistas como "pequenos adultos" sem nenhum papel social específico e até mesmo sem identidade, sendo vistas apenas como um "objeto substituível" (Airès, 1981/2012). Segundo Mendes e Ormerod (2019), com o fim da Idade Média e a eclosão de movimentos socioeconômicos e culturais como o lluminismo, Liberalismo e Revolução Industrial, a relação da sociedade com as crianças e a sua visão sobre elas foi mudando, semeando as compreensões de 'criança' e 'infância' que temos hoje. Os autores também afirmam que a política higienista do século XVIII e as suas ações para educar e formatar o atual modelo de "família nuclear" também ajudaram nesse processo. Porém, as raízes do PMICA surgiram alguns séculos antes por meio da doutrina parens patriae (Mendes \& Ormerod, 2019).

No século XIII, a Coroa Inglesa adotou o procedimento de tutelamento das pessoas que eram consideradas mentalmente incapazes, tais quais os 'loucos', 'idiotas' e 'lunáticos' (Funderburk, 2013). A ideia básica por trás dessa doutrina era de que o Rei, como parens patriae ("o pai da pátria") tinha o poder e o dever de proteger os mais fracos. Mais tarde, no século XVII, o parens patriae passou a ser atribuição das Cortes de Chancelaria inglesas, as quais eram incumbidas de proteger todas as crianças - analogicamente, tão incapazes quantos os loucos e débeis (Mendes \& Ormerod, 2019). Ao longo dos anos, os preceitos e a filosofia do "melhor interesse" se transferiram das cortes para os tribunais e a questão da proteção da criança foi se constituindo um instituto tradicional das normativas de vários países, indo desde as Cartas Magnas até os Códigos jurídicos.

No século XIX, na Pensilvânia, Estados Unidos, o melhor interesse da criança foi reconhecido pela corte daquele estado nas situações de divórcio. Contudo, esse interesse estaria ligado ao que se chamou de presunção de preferência materna para a atribuição da guarda, dando origem ao que se chamou de "Tender Years Doctrine" (ou Doutrina dos Tenros Anos). Esta doutrina pressupunha que a mãe, apenas por ser mulher e mãe, é quem detinha os requisitos e capacidades mínimas e essenciais para cuidar dos filhos e, assim, prover o seu melhor interesse (Azambuja, 2009; Machado \& Sani, 2015). Com o advento de mudanças socioculturais entre as décadas de 1970 e 1980, que repercutiram no Direito e depuseram a prática de se estabelecer um culpado pela ocorrência do divórcio, o que ensejava a desigualdade entre os gêneros, a Doutrina dos Tenros Anos foi sendo abandonada (Machado \& Sani, 2015). Contudo, ainda hoje é possível perceber alguns resquícios dessa doutrina, mas a atuação da Academia, de operadores do Direito e de associações de pais separados tem, cada vez mais, promovido a isonomia entre os gêneros no contexto da disputa de guarda, ampliando-se, assim, a compreensão e garantia dos melhores interesses dos filhos.

Na pós-modernidade, os debates e preocupações acerca do "melhor interesse da criança" ganharam força a partir do século XX. 0 primeiro documento instrumento jurídico internacional a oferecer diretrizes para a preservação dos direitos da criança foi a Convenção de Genebra, em 1924. Depois disso, em 1959 promulgou-se a Declaração Universal dos Direitos da Criança e a Convenção Internacional dos Direitos da Criança e do Adolescente (CDCA) em 1989.

Na Convenção de 1989, o PMICA pode ser sumarizado pelo artigo 3.1 que diz: "todas as ações relativas às crianças, levadas a efeito por instituições públicas ou privadas de bemestar social, tribunais, autoridades administrativas ou órgãos legislativos, devem considerar, primordialmente, o interesse maior da criança" [grifo nosso]. Desta forma, fica firmado que o PMICA tem como base o direito comum, apresentando-se como princípio norteador e balizador de impasses entre os direitos e interesses da criança/adolescente e os de outrem, como no caso da separação parental, no qual os interesses da criança/adolescente devem prevalecer sobre os de outras pessoas e/ou instituições (Azambuja, 2009; Mendes, BucherMaluschke, Vasconcelos, Souza \& Costa, 2016; Mendes \& Ormerod, 2019).

No Brasil, a confluência das ideias aventadas pela Declaração e pela CDCA ajudou a instituir o Estatuto da Criança e do Adolescente (ECA) - formalizando a transição da Doutrina de Situação Irregular para a Doutrina de Proteção Integral. A primeira doutrina era baseada no Código de Menores, instituído em 1927, que apresentava uma visão despontencializada da criança e do adolescente, com foco higienista, especialmente para com as crianças e adolescentes em situação de vulnerabilidade social. Esta doutrina tratava essas crianças e adolescentes como estando em uma "situação irregular", anormal, focando apenas no déficit. Já a outra doutrina passou a enxergar as crianças e adolescentes em sua totalidade, de forma integral e como foco em todas as crianças, não apenas aquelas em situação de vulnerabilidade social. Essa doutrina percebe a criança e o adolescente como sujeitos de direitos, construídos e construtores da realidade social.

Antes mesmo do ECA, a Constituição Cidadã de 1988 deu 


\section{W'INTERACÃO EM ET PSICOLOGIA}

destaque a esta Doutrina e ao PMICA, em especial, no seu artigo 227, que diz:

É dever da família, da sociedade e do Estado assegurar à criança e ao adolescente, com absoluta prioridade, o direito à vida, à saúde, à alimentação, à educação, ao lazer, à profissionalização, à cultura, à dignidade, ao respeito, à liberdade e a convivência familiar e comunitária, além de colocá-los a salvo de toda forma de negligência, discriminação, exploração, violência, crueldade e opressão [grifo nosso] (Brasil, 1988).

O termo "melhor interesse da criança" deriva da tradução do termo em Inglês "best interests of the child", o qual consta originalmente na Declaração Universal dos Direitos da Criança e também na Convenção. Em Português, é possível achar referências a esse princípio por meio dos termos "maior interesse da criança", "supremo interesse da criança" ou ainda "superior interesse da criança" - alguns autores podem utilizar 'menor' ou 'infante' para substituir 'criança'. Para Lauria (2003), o uso do "melhor" ao invés de "maior" ou "supremo" adequa-se mais por dar o devido destaque e importância à dimensão qualitativa do princípio e não a quantitativa.

Mendes et al. (2016), Mendes e Ormerod (2019) fazem uma reflexão importante quanto a referência ao PMICA no singular, "melhor interesse". Para os autores, dada à condição complexa e sistêmica de tal princípio, em especial na situação de divórcio e disputa de guarda, referir-se ao principio no singular pode passar a falsa ideia de que ele possa ser reduzido a um único aspecto, a apenas um interesse. Sendo assim, a proposta dos autores é de que se refira ao princípio no plural - Princípio dos Melhores Interesses da Criança/Adolescenre - já que "não só por sua condição humana, mas também por conta da sua condição peculiar de desenvolvimento, a promoção do bem-estar integral da criança envolve uma série de interesses, não apenas um" ( Mendes et al., p. 90).

Em seu trabalho sobre os fundamentos e padronização do PMICA na jurisprudência estadunidense, Kohm (2008) afirma que a operação do Direito evolvendo a definição da guarda e regime de visitação, a adoção, as situações de ilegalidade, a negligência e $O$ abuso cometidos contra crianças e adolescentes é regida pela égide do PMICA e que cabe ao juiz decidir o que é "melhor" para cada criança e em cada caso particular. A autora ainda reflete que a determinação desses melhores interesses é bastante desafiadora, pois convida, necessariamente, o magistrado a confiar em seus próprios valores e vieses para decidir em cada caso o que atende ao bem-estar biopsicossocial do infante. Além disso, esse princípio é marcado por uma insipiência jurídica para determinar e garantir o que são esses melhores interesses, além de levar em consideração as particularidades de cada criança e sistema familiar (Kohm, 2008; Mendes et al., 2016). Em função disso, faz-se extremamente necessário a integração de outras áreas do conhecimento nesse processo de avaliação e garantias, como Psicologia, Serviço Social, Medicina e etc (Lauria, 2003; Moraes, 2014; Mendes \& Ormerod, 2019).

Pensar e discutir o PMICA não é uma tarefa fácil (Funderburk, 2013; Sund \& Vackermo, 2015; Bobar, 2016), especialmente quando contextualizado nas situações de litígio familiar envolvendo a custódia dos filhos na Justiça. Amiúde, a disputa pela guarda dos filhos insere-se em um contexto de separação parental, logo, um contexto de crise. A crise que representa o processo de separação significa um momento bastante difícil e desafiador para o ciclo evolutivo de uma família. Lidar com a dor e angústia da frustração de sonhos, desejos, planos, sentimentos e investimentos emocional, psicológico e existencial torna esse momento bastante desafiador para a família como um todo (Mendes \& Bucher-Maluschke, 2017a). Além disso, tem-se também a ansiedade e o medo diante da necessidade de uma nova organização familiar que se impõe com o surgimento do divórcio.

Os sentimentos, angústias, ansiedades e tensões psicológicas geradas pela situação da separação parental podem guiar a família para um caminho de enfrentamento que não favoreça o seu bem-estar e a superação dessa fase evolutiva. Nos casos de disputa de guarda, deve-se sempre considerar os melhores interesses da criança, bem como as possíveis consequências emocionais causadas quando os direitos da criança/adolescente não são resguardados. Diante desse contexto, tem-se: como reconhecer e garantir os melhores interesses da criança/adolescente no contexto de disputa de guarda?

Cabe aos atores jurídicos (juízes, promotores, advogados, psicólogos e assistentes sociais), responsáveis por atender esta demanda, a difícil missão de tentar delimitar algo que tem as idiossincrasias de um princípio que se pretende norteador de ações e julgamentos no âmbito da Justiça (Mendes \& Bucher-Maluschke, 2017b). Outra tarefa ardilosa é pôr esse princípio em prática durante a análise do processo, a feitura de estudo psicossocial e despacho de sentenças. 0 desafio que se configura para esses atores é conciliar e harmonizar as demandas da Justiça - que se referem ao rito do processo e a resolução do conflito -, favorecer o bemestar e a reorganização familiar e, principalmente, manter os interesses da criança/adolescente em primeiro lugar.

Diante desse cenário, o presente estudo investigou as concepções e práticas dos atores jurídicos - juiz, promotor, psicólogo, assistente social -, atuantes nos casos de disputa 


\section{W'INTERACÃO EM ET PSICOLOGIA}

de guarda, acerca do Princípio dos Melhores Interesses da Criança/Adolescente.

\section{MÉTODO}

Este estudo foi qualitativo, exploratório e descritivo, estruturando-se por meio de um método de análise fundamentado na construção de Zonas de Sentidos propostas por González Rey (2005). Esse tipo de análise caracteriza-se por ser essencialmente construtivointerpretativa. O princípio dessa análise é composto por processos reflexivos que se integram e desintegram ao longo da produção teórica, que transbordam os processos de indução e dedução, estando em constante movimento, gerando o processo de construção de informações acerca daquilo que está sendo pesquisado (González Rey, 2005).

Esse processo é considerado dialógico-hipotético a partir da construção das informações que culminam na formação de núcleos do sentido. Estes núcleos de sentido não são construídos de forma rígida e não são constituídos pelos pontos mais frequentes, mas sim pelo o que mais significa para os sujeitos entrevistados (Arrais, 2005). Diante disso, podem ser elaboradas zonas de sentido, que valorizam o conhecimento e a formação de sentidos e significados para o discurso e produção subjetiva dos sujeitos, capitados pelo processo de pesquisa qualitativa.

\section{INSTRUMENTO E PARTICIPANTES}

O instrumento utilizado foi a entrevista semiestruturada individual. Foram entrevistados um juiz, um promotor, uma psicóloga e uma assistente social, todos atuantes em uma Vara de Família de uma cidade satélite do Distrito Federal e amostrados por conveniência. Todos os participantes tinham mais de cinco anos de experiência na Vara de Família, com exceção da assistente social, que estava nesse serviço há aproximadamente três anos. Os participantes foram entrevistados em seus gabinetes (Varas e Promotorias de Família) e/ou escritórios (Psicóloga e Assistente Social). Foram conduzidas e gravadas as entrevistas semiestruturadas mediante roteiro de entrevista pré-definido de acordo com os objetivos da pesquisa.

\section{RESULTADOS E DISCUSSÃO}

$\mathrm{Na}$ análise, todos os participantes da pesquisa foram entendidos como atores jurídicos que atuam no processo de disputa de guarda. 0 juiz (Jz) e o promotor (Pr) são qualificados como operadores do Direito e a assistente social (As) e a psicóloga (Ps) são entendidas como profissionais forenses.

A seguir são apresentados conjuntos de resultados vinculados às Zonas de Sentido. 0 primeiro conjunto engloba a Zona de Sentido 01 e 02, que evidenciam como os atores jurídicos compreendem os melhores interesses da criança/ adolescente, elencando elementos essenciais para a sua garantia, tendo ele uma dimensão jurídica - das leis - e psicossocial - ligados a fatores do desenvolvimento biopsicossociocultural da criança e do adolescente. 0 segundo conjunto apresenta os resultados referentes à Zona de Sentido 03, que reflete a compreensão dos atores jurídicos sobre o divórcio e como ele atravessa as questões de disputa de guarda e o PMICA. Por fim, tem-se a apresentação dos resultados da Zona de Sentido 04, que fazem referência à necessidade de se compreender e intervir na família compreendendo-a como um sistema.

Zona de Sentido 01: a dimensão jurídica-psicossocial dos Melhores Interesses da Criança/Adolescente - "é um princípio que inspira normas e se preocupa com o bem-estar da criança"

Os atores jurídicos demonstraram ter uma concepção convergente acerca do PMICA. Contudo, ressalta-se a dificuldade, por parte dos operadores do Direito, em definir o que seria esse princípio.

"É difícil a gente dar uma definição do que é o melhor interesse da criança, porque se trata de um princípio, aonde ele tem que se apresentar como uma norma mais aberta" (Pr)

\section{"É um conceito vago de propósito" (Jz)}

"Na condição de princípio, ele passa a ser uma norma inspiradora das normas que dizem respeito à melhor proteção do interesse do menor" (Pr)

Para os operadores do Direito, o PMICA apresenta-se como vago e tendo a função de nortear ações jurídicas. Esse princípio seria, então, uma norma inspiradora de ações ou até mesmo de outras normas que fazem referência a ele.

Zawati, Parry \& Knoppers (2014), Nevondwe, Odeku \& Raligilia (2016) e Kalverboer, Beltman, Van Os, \& Zijlstra (2017) apontam que a dificuldade em estabelecer conceitualmente esse princípio é comum, uma vez que sua compreensão estaria à mercê das particularidades de cada caso - além da subjetividade de cada um dos atores jurídicos envoltos -, podendo, então, conforme apontado pelos operadores do Direito, o princípio ser compreendido como uma diretriz. O PMICA funda-se na CDCA, a qual estabelece e garante direitos humanos básicos às crianças $e$ adolescentes, sendo, porquanto, o PMICA um tipo de direito 


\section{W'INTERACÃO EM ET PSICOLOGIA}

humano (Zermatten, 2010). Essa "inconsistência" do princípio é uma característica comum a todos os direitos humanos (Pomerance, 2013; Sormunen, 2016). Quando se pensa no contexto das famílias e da disputa de guarda, essa característica torna-se importante à medida que cada família tem a sua dinâmica própria, não funcionando, necessariamente, de forma análoga a outros sistemas familiares. Assim, a flexibilidade do PMICA, apesar de muito criticada, é um aspecto positivo, pois, desta forma, pode contemplar a pluralidade das configurações e dinâmicas familiares. Além disso, essa característica também permite que cada país, a partir da sua cultura e seu sistema jurídico, possa fazer as adaptações necessárias para a promoção do PMICA.

Os operadores do Direito evidenciaram que os melhores interesses da criança/adolescente estão ligados a duas dimensões: (a) jurídica e (b) psicossocial. A dimensão jurídica se faz por meio do entendimento de que o PMICA é um princípio jurídico, essencialmente, além de estar garantido e previsto em várias normativas nacionais e internacionais.

"O melhor interesse da criança é um principio constitucional. Esse princípio acaba decorrendo da garantia constitucional de proteção integral da criança e que veio ser regulamentado pelo ECA" (Pr)

"[o melhor interesse] se foca no bem-estar dessa criança, na condição de pessoa em desenvolvimento, merecendo toda uma atenção no que toca a proteção de direitos fundamentais, em especial: vida, liberdade, dignidade, convivência familiar e comunitária" (Jz)

Essas falas sugerem que, juridicamente, esses interesses são promovidos quando há a garantia de direitos fundamentais, como direito à vida, à liberdade, à dignidade, além do provimento de segurança e acesso à educação, saúde e lazer. Como visto na fala dos operadores do Direito, a dimensão psicossocial está ligada à garantia da convivência familiar, que, apesar de se constituir juridicamente, foi abordado pelos atores jurídicos como importante fator para o desenvolvimento e constituição da personalidade das crianças/adolescentes e promoção de afetividade.

Os atores jurídicos também destacaram a questão da preservação da criança/adolescente em relação aos danos psicológicos contingenciados pela separação:

"Principalmente tranquilidade. A criança precisa ser poupada do ambiente de hostilidade que envolve a disputa" (Jz)

"Proteção em primeiro lugar" (As)

"[é a criança] ter essa liberdade, essa permissão de todas as pessoas, de você não ter que fazer uma aliança, de você poder caminhar, de você estar livre para poder ir e vir de qualquer maneira, de acordo com sua vontade, seu interesse" (Ps)

"Em que medida ele [genitor] protege, educa, estabelece limites, deixa a criança livre, em que medida que ele tem expectativas que a criança tenha lealdade com ele, com as dores dele. Eu acho que isso é fundamental" (Ps)

As profissionais forenses trouxeram uma preocupação maior no que se refere à liberdade da criança/adolescente no contexto da disputa. Elas apontam que é importante preservar a liberdade de ir e vir da criança/adolescente, de não ser colocada no meio da disputa, mediando conflitos ou fazendo alianças. Essa é uma preocupação importante, pois, de acordo com Juras e Costa (2011) e Mendes \& BucherMaluschke (2017a), muitas vezes, as crianças/adolescentes são trianguladas (envolvem-se no conflito para tentar diminuir a tensão no subsistema conjugal) nos conflitos parentais, colocadas como mediadoras ou ainda parentalizadas (quando as crianças/adolescentes assumem papeis e funções parentais). Assim, estabelecer meios para a preservação emocional da criança/adolescente durante o processo de disputa de guarda é fundamental para garantir os seus melhores interesses.

Zona de Sentido 02: a primazia pela convivência familiar como garantia dos Melhores Interesses da Criança/ Adolescente - "É preciso preservar o direito à convivência familiar"

Para os atores jurídicos, as dimensões jurídicas e psicossociais dos melhores interesses da criança e do adolescente em situação de disputa de guarda convergem em um só sentido, a garantia do direito à convivência familiar:

"Há uma preocupação, nesses casos de disputa de guarda, de permitir com que a criança tenha garantido o seu direito de convivência familiar" (Pr)

"A criança precisa de valores a serem transmitidos por ambos os genitores, ambos são peças fundamentais no desenvolvimento desse menor" (Pr)

“(...) [a gente] busca que a criança tenha uma rotina mais próxima possível daquela situação anterior, quando o casal estava junto, morando juntos (...) para que a criança possa continuar a ter convivência com os dois [genitores]" (Pr)

"Respeitar a criança no direito dela de amar e ser amada, ser protegida, ser cuidada por todas aquelas pessoas que estão ao redor dela e que precisam fazer isso por ela, pessoas que são responsáveis por ela" (Ps)

Ao analisar essas falas, é possível depreender que os 


\section{W'INTERACÃO EM PSICOLOGIA}

atores jurídicos entendem a garantia da convivência familiar, com o pai e a mãe descasados (a exemplo do modelo hegemônico de família), como a principal forma de manutenção e asseguramento dos interesses da criança/ adolescente nos casos de disputa de guarda. Para eles, a criança/adolescente precisa das referências e dos cuidados de ambos os genitores para poder ter um desenvolvimento congruente. Isso corrobora a ideia de que os pais têm um papel fundamental no desenvolvimento psíquico, emocional, social e cultural dos filhos (Ribeiro, 2010).

Outro aspecto importante da garantia do convívio familiar é a preservação da convivência com os valores culturais parentais. É direito da criança/adolescente e atende aos seus interesses que, através da convivência com ambos os pais, ela possa, dialeticamente, encontrar um senso de identidade e pertencimento nos valores culturais de cada genitor. Essa acepção tem ressonância com as prerrogativas do Estatuto da Criança e do Adolescente, que em seu artigo 28, $\S 6^{\circ}$, inciso I, estabelece que "sejam consideradas e respeitadas sua identidade social e cultural, os seus costumes e tradições" [grifo nosso].

Essa primazia pela convivência familiar, enquanto elemento principal na garantia dos melhores interesses da criança/adolescente possivelmente seja o que levou a alteração dos artigos 1.583, 1.584, 1.585 e 1.634 do Código Civil Brasileiro (CDC) por meio da Lei $n^{\circ} 13.058 / 2014$, 'Lei da Guarda Compartilhada'. A lei alterou o $\S 2^{\circ}$ do artigo 1.583 do CDC, estabelecendo que "na guarda compartilhada, o tempo de convívio com os filhos deve ser dividido de forma equilibrada com a mãe e com o pai, sempre tendo em vista as condições fáticas e os interesses dos filhos". Essa alteração traz dois pontos. O primeiro é justamente a confirmação da primazia pela convivência familiar ao estabelecer o tempo de convívio equilibrado entre os dois genitores. Decorrente do primeiro, o segundo ponto refere-se à letra da lei que afirma: "o tempo de convívio com os filhos deve ser dividido de forma equilibrada com a mãe e com o pai". Isso pode levar a uma interpretação limitada da lei ao construir uma compreensão sobre a guarda compartilhada enquanto uma modalidade de guarda alternada. Esse tipo de guarda estabelece um arranjo no qual a presença física da criança/adolescente é compartilhada igualmente, levando ao convívio alternado da criança/adolescente entre as casas de ambos os genitores em uma frequência diária, semanal, mensal ou anual (Silva, 2013). No Direito e na Psicologia, a aplicação de arranjos de guarda assemelhados à alternada é bastante polêmica, havendo uma significativa corrente contrária à sua implementação (Bemfica, 2001). 0 aspecto que mais se opõe a esse tipo de guarda é a necessidade de estabilidade (física, social e psicoemocional) para o desenvolvimento congruente da criança/adolescente (Bronfenbrenner \& Morris, 1998;
Bronfenbrenner, 2005; Collodel-Benetti, Vieira, Crepaldi \& Ribeiro-Schneider, 2013). Em tese, a alternância de convivência física prejudicaria a manutenção da percepção de rotina, referências (de lar, por exemplo) e segurança da criança/adolescente, logo, a sua percepção de estabilidade. Assim, pensando nos melhores interesses da criança/ adolescente, o melhor seria a manutenção da sua percepção de estabilidade. De toda sorte existem casos, especialmente aqueles em que, por meio de autocomposição, antes da chegada à Justiça e/ou no entremeio de uma decisão judicial e outra, um arranjo análogo à guarda alternada já se estabeleceu e a criança/adolescente está adaptada e bem. Neste caso, a manutenção dos melhores interesses da criança/adolescente, por conseguinte da sua percepção de estabilidade, seria justamente manter esse arranjo. Assim, a atuação de equipe psicossocial multiprofissional para a avaliação de cada caso é essencial para a compreensão e manutenção dos melhores interesses da criança/adolescente de acordo com o contexto no qual ela está inserida.

A 'Lei da Guarda Compartilhada' também alterou o $\S 2^{\circ}$ do artigo1.584 do CDC, estabelecendo que "quando não houver acordo entre a mãe e o pai quanto à guarda do filho, encontrando-se ambos os genitores aptos a exercer o poder familiar, será aplicada a guarda compartilhada”. Tal qual o aspecto da divisão igualitária de tempo, a atribuição de guarda compartilhada, preferencialmente, em todos os casos e, em especial, nos que não há acordo entre as partes parece ser problemática, quando se pensa nos interesses da criança/ adolescente. O primeiro problema é que a definição de guarda, em especial a compartilhada, deveria ser feita de acordo com a história do ex-casal, a dinâmica das disputas pré e pós-divórcio, a idade das crianças/adolescentes, os traços de personalidade dos pais, os padrões interacionais da relação parento-filial e as potencialidades do modelo de coparentalidade exercido pelos genitores (Lago \& Bandeira, 2009). A primeira pergunta a ser feita, em cada caso, deveria ser: esse arranjo privilegia mais os interesses de quem, dos genitores ou da criança/adolescente? A garantia de conivência familiar com ambos os genitores, sem sombra de dúvidas, atende aos melhores interesses da criança/ adolescente. Contudo, não pode ser uma convivência a todo custo. Uma convivência familiar cercada por uma coparentalidade com comunicação disfuncional, com alta tensão psicoemocional, constantes e pequenas disputas de poder que acirram a beligerância e a disputa é bem mais prejudicial ao desenvolvimento psicoemocional da criança/ adolescente e seus interesses do que uma convivência familiar limitada (em função da guarda unilateral e/ou qualquer outro arranjo em que o tempo de convívio físico não seja o principal aspecto). Novamente, a atuação da equipe multiprofissional para a avaliação de cada caso e melhor 


\section{W NTERAC̄OOEM ET. PSICOLOGIA}

compreensão de quais interesses da criança/adolescente é vital.

Ao final, o que importa dizer é que os melhores interesses da criança/adolescente (e a manutenção da sua percepção de estabilidade) é que devem ser o guião principal para o estabelecimento do tipo de guarda, levando-se sempre em consideração o contexto relacional ao qual a criança pertence (família, escola, comunidade, pares), bem como as potencialidades e realidade relacional de cada família (qual a capacidade dessa família? Que arranjo de guarda atendendo aos melhores interesses da criança - essa família consegue manter? Qual arranjo de guarda, adequando-se a essas capacidades relacionais, favorece a saúde mental de toda a família, mas especialmente da criança/adolescente?).

Complementar a isso, os atores jurídicos apontam que, para a promoção dos melhores interesses da criança/ adolescente, é importante que, de fato, se possa reconhecer a criança e o adolescente como sujeitos de direitos e que, nesse sentido, eles também possam ser ouvidos, que the possa ser oferecido um espaço legítimo no qual a sua fala possa ser reconhecida. Essa prerrogativa é fundamental, pois a CDCA em seu artigo $12^{\circ}$ estabelece que se deve garantir "(1) à criança com capacidade de discernimento o direito de exprimir livremente a sua opinião sobre as questões que the respeitem, sendo devidamente tomadas em consideração as opiniões da criança, de acordo com a sua idade e maturidade" e que a ela deve ser dada "(2) a oportunidade de ser ouvida nos processos judiciais e administrativos que the respeitem". Reconhecer essa prerrogativa é ratificar a condição de 'sujeito de direitos' que a CDCA confere às crianças/adolescentes. Nos casos de disputa de guarda, isso se torna ainda mais importante, pois, segundo Ribeiro (2010), nos processos em que os interesses da criança/adolescente estão em foco, ela própria criança acaba sendo desqualificada enquanto sujeito no processo de decisão de guarda, onde a sua escuta deveria ser prioritária e essencial no decorrer do processo de tomada de decisão sobre a guarda. Cabe ressaltar, como aponta o próprio artigo da CDCA, que se deve levar em conta a idade e maturidade da criança e o mais importante: deve ser retirado dela qualquer sombra de responsabilidade em relação à decisão sobre a guarda. Ou seja, a criança/adolescente deve ser preservada da posição de escolha entre um dos genitores - como alguns atores jurídicos insistem em coloca-las -, pois, independente dos fatos e acontecimentos, a criança/adolescente continua tendo ligações afetivas importantes com ambos os genitores e ser imputado a ela tal escolha pode acarretar significativos problemas psicossociais e psicoemocionais por conta dos conflitos de aliança e afeto.

Em relação aos interesses, os atores jurídicos apontam uma visão para além das necessidades materiais da criança/ adolescente:

"Os interesses não são só interesses materiais, não são só se ele está bem alimentado, ou se está estudando em uma boa escola" (As)

“(...) e aí a gente tem que olhar o lado da proteção, tem o lado financeiro, mas não é um lado que assume relevância no momento de se decidir uma guarda" (Pr)

Essa concepção de um princípio jurídico que extrapole as letras da lei e garantias objetivas, como a provisão de alimentos, evidencia a evolução do pensamento humano que provoca no Direito, como uma ciência social, um eterno processo de adaptação (Paes \& Amin, 2010). Isso implica dizer que os operadores do Direito não podem aplicar a lei de forma acrítica, pois eles são um agente político, além de estarem inseridos no contexto sócio histórico e cultural do país. A negação desse aspecto pode aviltar não apenas os interesses da criança/adolescente, mas também a saúde emocional dos operadores do Direito, por meio da ocorrência de burnout e traumatização secundária (Mendes \& BucherMaluschke, 2017b).

Zona de Sentido 03: (In)compreensões sobre o processo de divórcio - "o divórcio é uma experiência traumática e inesperada"

O discurso dos participantes aponta duas concepções para a situação de separação conjugal: (1) o divórcio como parte do Ciclo de Vida das Famílias e (2) o Divórcio como trauma. As duas compreensões apresentam diferentes implicações na garantia dos melhores interesses dos filhos.

"A separação, na verdade, é uma coisa traumática para todos. É um projeto de vida e de felicidade que deu errado" (Jz)

"A situação de separação é uma mudança na vida das pessoas que, muitas vezes, as pessoas não esperavam" (Jz)

Para os operadores do Direito entrevistados, a separação é uma mudança na vida das pessoas que não é esperada, sendo, por vezes, traumática para todos da família. Assim, ela pode também representar um projeto de felicidade que deu errado e isso leva às famílias a uma situação de sofrimento e conturbações que acabam afetando as crianças/ adolescentes.

Essa compreensão dos operadores do Direito possivelmente é espelhada no processo de formação acadêmica deles, vez que o Direito, em função da sua compleição prática e epistemológica, parece não oferecer 


\section{WIINTERACÃO EM ET PSICOLOGIA}

subsídios para uma percepção do divórcio para além do trauma, do erro, do déficit (Mendes et al. 2016).

"A separação sempre é uma possibilidade de uma vida com melhor qualidade. Ela pode ser uma saída saudável para uma família" (Ps)

Essa ideia da separação como uma mudança na vida das famílias é consoante com a compreensão de que o divórcio pode fazer parte do ciclo vital da família (Bucher-Maluschke, 2017a). Esse processo exige inicialmente uma adaptação e uma vivência do luto pelo casamento desfeito (Lima \& Campos, 2003; Souza \& Miranda, 2009). Se isso não acontece, a tendência é que os conflitos e a litigância aumentem, fazendo com que a vivência do divórcio seja mais traumática e dolorosa do que poderia ser, levando a família a uma situação de divórcio destrutivo e consequente prejuízo aos melhores interesses dos filhos (Mendes \& BucherMaluschke, 2017a).

Em certa medida, as percepções da psicóloga e do juiz coadunam na perspectiva do divórcio como um momento de crise, um período conturbado para a família, de difícil aceitação e transposição. Contudo, a psicóloga parece focar mais nas potencialidades do divórcio, enquanto uma mudança na vida das famílias, que pode levar a uma melhor qualidade de vida dos seus membros - a depender da forma como é encarado e vivenciado.

O divórcio não é o fim da vida da família, mas apenas uma das transformações possíveis ao longo do seu ciclo vital. Os litigantes continuam sendo membros de uma família, só que uma família descasada ou bi-nuclear. Costa (1991) vai além ao entender que a família descasada pode possuir as mesmas habilidades e competências que qualquer outra configuração familiar, podendo ser a separação, então, a representação de um movimento de mudança necessário e inevitável no padrão relacional da família. Essa mudança não é, per si, boa ou ruim, é apenas uma mudança na qualidade da interação familiar, que será vivenciada e qualificada de acordo com o movimento das relações e interações que a família mantém dentro e fora dela.

O divórcio se inscreve no processo natural do desenvolvimento familiar e é entendido como parte integrante do Ciclo de Vida das Famílias. Nesse prisma, apesar da flagrante situação de crise que pode levar a uma ligeira desorganização do sistema familiar, o divórcio, enquanto etapa de desenvolvimento da família, tem potencial para que o ex-casal e a família possam superar e dar conta da instabilidade e carga emocional que a separação dos cônjuges pode proporcionar. Assim, a família conseguirá passar para a sua próxima etapa de desenvolvimento, preservando o seu bem-estar e, especialmente, os melhores interesses dos filhos.

Aliado a essa realidade, como um fator complementar, existe outro obstáculo que permeia a avaliação e garantia do PMICA: a compreensão e separação dos papéis conjugais do papéis parentais. A relação entre esses papéis parece ser um dos grandes desafios para a garantia desse princípio, após a separação parental. Conforme apontam os atores jurídicos:

"Muitas vezes, a gente inicia um processo onde as pessoas estão muito ressentidas, muito magoadas e não conseguem enxergar o menor no meio daquilo, aonde o menor é utilizado como uma forma de manifestar poder" (Pr)

"A separação, às vezes, é feita em um ambiente de mágoa, de dificuldade e ninguém busca lembrar-se da criança, como vai ser situação do filho, os pais e mães acham que estão se separando, mas não se separam dos filhos" (Jz)

"É muito comum que os pais, na disputa de guarda, muitas vezes estejam visando seus próprios interesses" (As)

"O aprisionamento [no conflito] é tão grande que ficam tão cegos às necessidades afetivas daquela criança" (Ps)

Separar os papéis conjugais dos parentais tem se mostrado, nos casos de disputa de guarda, realmente a maior dificuldade dos ex-casais (Santos \& Fonseca, 2003, Ribeiro, 2002, 2010; Mendes \& Bucher-Maluschke, 2016; Mendes \& Bucher-Maluschke, 2017a). Isso ocorre porque o par parental estabelece uma dinâmica na qual um avalia o desempenho parental do outro a partir do desempenho conjugal apresentado no decorrer da vida conjugal. Além disso, as fronteiras filiais, parentais e conjugais ficam difusas, pois as interações familiares pós-separação parental se ocupam em evitar a elaboração do sofrimento e do luto, o que pode levar a família a um prejuízo no seu desenvolvimento (Costa, Penso, Legnani \& Sudbrack, 2009; Juras \& Costa, 2011).

Para os atores jurídicos, em especial os operadores do Direito, o que ocorre também é que, ao não diferenciar aqueles papéis e não se preocupar com a situação dos filhos, esses pais passam a entrar em uma disputa de poder, na qual o filho é tido como um prêmio a ser conquistado:

"Muitos aí entendem a criança como um troféu na hora da separação, então isso já revela uma imaturidade para estar com a criança" (Jz)

A ideia da criança/adolescente como um prêmio evidencia a perversidade que pode permear a disputa de guarda. Isso porque esse contexto pode ser marcado pelo empenho dos pais na busca de maior poder, ignorando o bem-estar dos filhos (Juras \& Costa, 2011). Diante dessa 


\section{W'INTERACÃO EM PSICOLOGIA}

complexidade, o que aparece como um desafio para os operadores do Direito é como conciliar os direitos fundamentais da criança/adolescente, como o direito à convivência familiar e a preservação de outros interesses, quando a própria convivência com o genitor se apresenta como aviltante para criança/adolescente, a exemplo dos casos em que há uma dificuldade em se diferenciar as questões conjugais das parentais.

Zona de Sentido 04: A Intervenção Psicossocial a Nível de Sistema Familiar como Forma de Promover os Interesses da Criança e do Adolescente - "trabalhar em função do sistema, mas com o foco na criança"

As profissionais forenses frisam que, para a real promoção dos melhores interesses da criança/adolescente, é preciso compreender e lidar com a família como um sistema, colocando o estudo psicossocial em função do sistema, mas com foco na criança. A própria primazia pela convivência familiar - compartilhada por todos os atores jurídicos - ao situar o bem-estar da criança e do adolescente no seu contexto familiar já evidencia a necessidade de se intervir junto à família e promovendo o PMICA a nível de sistema.

"A gente não trabalha com questões isoladas, a gente trabalha com o conjunto da obra, com as questões que envolvem o sistema familiar" (As)

"Eu acho que a gente trabalha em função de um sistema e o foco é ela [a criança]" (Ps)

Em linhas gerais, um sistema é um conjunto de elementos, unidades, em constante inter-relação circular e interdependente (Mendes et al. 2016). Isso significa dizer que o sistema é mais que a soma de suas partes, é produto das interações entre os seus elementos e dos seus padrões. No caso da família, isso se traduz na ideia de que, em um sistema familiar, todos participam da construção do seu modo de funcionamento e todos os membros estão ligados de tal forma que qualquer mudança e/ou alteração em algum deles irá repercutir, em algum nível, em todo o sistema e em cada um deles. Isso ajuda a compreender porque a situação de separação parental não atinge apenas os ex-cônjuges, mas a família como todo e porque, como apontado pelas profissionais forenses, pensar a promoção do PMICA é pensá-lo inserido em um sistema como um todo e não só em relação à criança. Dessa forma, elas entendem que, para a criança estar bem, é preciso que a família, como sistema protetor, também esteja. Além disso, compreendem que o estudo psicossocial deve ir além do par parental e até mesmo da família, indo buscar a rede social de proteção que envolve a criança/adolescente.

Essa percepção deriva da compreensão de que o estudo é centrado na criança/adolescente, mas ela não pode ser isolada do contexto no qual os seus interesses, em primeira instância, são ou não respeitados: a família. Isso é pertinente quando se entende que, enquanto sistema, a família é uma complexa rede de relações na qual o indivíduo, no caso a criança/adolescente, cresce e se desenvolve, formando a sua identidade e adquirindo referências de pertencimento e desenvolvendo a sua autonomia (Lima \& Campos, 2003). Nesse sentido, é necessário a instauração de uma intervenção mais holística que possa legitimar, apontar e preservar o PMICA na sua inter-relação com os seus contextos. Mendes e Ormerod (2019) corroboram essa ideia e ampliam-na ao incluir também a comunidade, a escola, os sistemas de garantias básicas (como de saúde e assistência social) e os macrossistemas de políticas públicas voltadas para a criança/adolescente e o seu bem-estar. Desta forma, existe uma rede de inter-relações retroalimentativas que compõem o contexto do bem-estar da criança/adolescente e da família. A criança está inserida em seu sistema familiar que, como já dito, atua como o principal sistema protetor da criança/adolescente. A família, por sua vez, encontra-se inserida em um sistema de redes de apoio formal ou informal que podem ter atuação sobre o bem-estar da família; logo, também sobre o da criança/adolescente. Assim, não é possível desmembrar a criança/adolescente desses contextos dos quais ela faz parte e se vincula, por conta da sua condição sistêmica nessas interações. Desse modo, toda e qualquer intervenção junto ao par parental deve levar em conta esses contextos, inevitavelmente

\section{CONSIDERAÇ̃̃ES FINAIS}

De modo geral, o PMICA foi referido como um princípio vago, sem objetividade e determinação. Essa característica, além de própria de qualquer direito humano - identidade prima do PMICA -, é também desejável para o encaixe nas diversas formas de família e práticas de políticas públicas de cada país. O PMICA foi entendido como um princípio de duas dimensões: (1) jurídica: referente à norma, leis; (2) psicossocial: referente à afetividade e garantia da convivência familiar. Além disso, para os atores jurídicos é de fundamental importância, para a promoção do PMICA, a preservação emocional e afetiva da criança/adolescente durante o processo de disputa de guarda. Outro aspecto importante é a compreensão da criança/adolescente como sujeito de direitos, sendo-lhe garantida o direito à fala e à expressão de ideias durante o processo, sem, contudo, atribuir-lhe o poder de decisão final. Por fim, outra questão que permeia o PMICA é a situação de separação parental e as suas implicações para o sistema familiar. Neste sentido, as instabilidades geradas pela separação e a confusão entre 


\section{Ha mereacio ET. PSICOLOGIA}

os papeis parentais e conjugais mostram-se como grandes desafios para a manutenção do PMICA, juntamente com alguns interesses da criança/adolescente que podem ser conflitantes entre si. Por isso, para a promoção do PMICA é necessária uma atuação holística sobre a criança/ adolescente, sua família e os demais contextos pertinentes. A necessidade de uma maior articulação entre os atores jurídicos (juízes, promotores, psicólogos e assistentes sociais forenses, advogados) e outros atores não jurídicos (escola, comunidade, serviços de saúde, etc.) que têm participação direta e ativa na promoção dos interesses da criança/ adolescente é fundamental para a consolidação de um trabalho interdisciplinar e também para a constituição de uma rede de proteção à criança/adolescente e de apoio à família.

Embora contribua para uma compreensão mais ampla sobre o tema, este estudo tem suas limitações, pois foi realizado com um grupo de profissionais que atuam em um nicho restrito, o que torna a percepção deles circunscrita a esse campo relacional e profissional. Além disso, não foi possível investigar as percepções e práticas dos advogados, os quais também são autores-chaves no processo de divórcio e, por conseguinte, de promoção do PMICA neste contexto. De todo modo, os resultados e as discussões aqui apresentados poderão contribuir para uma discussão ampla sobre o PMICA, sua definição e operacionalização; talvez até inspirando a condução de novos, diversos e aprofundados estudos.

\section{DECLARAÇÃO DE FINANCIAMENTO}

A pesquisa relatada foi financiada parcialmente pela bolsa de doutorado do primeiro autor (CAPES, Doutorado Pleno no Exterior, Processo nº 88881.127899/2016-01).

\section{DECLARAÇÃO DE CONFLITOS DE INTERESSE}

Os autores declaram que não há conflitos de interesse no manuscrito submetido.

\section{REFERÊNCIAS}

Arrais, A. R. (2005). As configurações subjetivas da depressão pós-parto: para além da padronização patologizante (Tese de Doutorado). Departamento de Departamento de Psicologia Clínica, Universidade de Brasília.
Azambuja, M. R. F. (2009). A inquirição da vítima de violência sexual intrafamiliar à luz do melhor interesse da criança. In: Falando sério sobre a escuta de crianças e adolescentes envolvidos em situação de violência e a rede de proteção: propostas do Conselho Federal de Psicologia. Brasília: Conselho Federal de Psicologia, 27-70.

Balestero, G. S., \& Bahia, A. G. M. F. (2011). O Melhor Interesse Da Criança: A Adoção Homoafetiva No Direito Brasileiro. Revista Jurídica Cesumar-Mestrado, 11(1), 247-268. doi: 10.17765/2176-9184.2011v11n1p\%25p

Bemfica, I. F. C. (2001). Aspectos psicológicos da guarda compartilhada no direito brasileiro (Dissertação de Mestrado). Universidade Federal de Santa Catarina.

Bobar, C. F. (2016). Considerations on the Best Interests of the Child as a Principle of Exercising Parental Authority. Journal of Legal Studies, 18(32), 88-96. doi: 10.1515/jles2016-0018

Bronfenbrenner, U., \& Morris, P. A. (1998). The ecology of developmental processes. In: Handbook of child psychology, Vol. 1: Theoretical models of human development. New York: John Wiley \& Sons, Inc.

Bronfenbrenner, U. (2005). Making human beings human: Bioecological perspectives on human development. Thousand Oaks, CA: Sage Publications Ltd.

Brasil. (1988). Constituição da República Federativa do Brasil. Brasília: Senado.

Collodel-Benetti, I., Vieira, M. L., Crepaldi, M. A., \& RibeiroSchneider, D. (2013). Fundamentos de la teoría bioecológica de Urie Bronfenbrenner. Pensando Psicología, 9(16), 89-99. doi: 10.16925/pe.v9i16.620

Costa, L. F. (1991). A família descasada: uma nova perspectiva. Psicologia: Teoria e Pesquisa, 7(03), 229-246. doi: 10.1590/S0102-79721999000100010

Costa, L. F., Penso, M. A., Legnani, V. N., \& Sudbrack, M. F. O. (2009). As competências da Psicologia Jurídica na avaliação psicossocial de famílias em conflito. Psicologia \& Sociedade, 21(2), 233-241. doi: 10.1590/S010271822009000200010

Funderburk, C. (2013). Best Interest of the Child Should Not Be an Ambiguous Term. Children's Legal Rights Journal, 33, 229-266.

González Rey, F. L. (2005). Pesquisa qualitativa e subjetividade: os processos de construção da informação. São Paulo: Pioneira Thomson Learning.

Juras, M. M., \& Costa, L. F. (2011). O divórcio destrutivo na perspectiva de filhos com menos de 12 anos. Estilos da clínica, 16(1), 222-245. doi: 10.11606/issn.19811624.v16i1p222-245 


\section{W'INTERACÃO EM PSICOLOGIA}

Kalverboer, M., Beltman, D., van Os, C., \& Zijlstra, E. (2017). The Best Interests of the Child in Cases of Migration. The International Journal of Children's Rights, 25(1), 114-139. doi: 10.1163/15718182-02501005

Kohm, L. M. (2008). Tracing the foundations of the best interests of the child standard in American jurisprudence. Journal of Law and Family Studies, 10(1), 337-376. doi: 10.2139/ssrn.1957143

Lauria, F. G. (2003). A regulamentação de visitas e o princípio do melhor interesse da criança. Rio de Janeiro: Lumen Juris.

Lago, V. D. M., \& Bandeira, D. R. (2009). A Psicologia e as demandas atuais do direito de família. Psicologia: ciência e profissão, 29(2), 290-305. doi: 10.1590/s1414$98932009000200007 i$

Lima, H. G. D., \& Campos, N. M. V. (2003). A Importância da Subjetividade nos Processos de Família: A Desconstrução da Disputa. In: Lima, H. G. D (Org.). Construindo Caminhos para a Intervenção Psicossocial no Contexto da Justiça. Brasília: Tribunal de Justiça do Distrito Federal e Territórios.

Machado, M. L., \& Sani, A. I. (2015). Parentalidade e tomada de decisão judicial nos processos de regulação do exercício das responsabilidades parentais. Revista do Centro de Estudos Judiciários, 1(1), 195-208

Mendes, J. A. A., \& Bucher-Malusche, J. S. N. F. (2017b). Coping e racionalização: Atuação de advogados nos casos de disputa de guarda. Interação em Psicologia, 21(3), 230238. doi: 10.5380/psi.v21i3.51414

Mendes, J. A. A., \& Bucher-Maluschke, J. S. N. F (2017a). Destructive divorce in the Family Life Cycle and its implications: criticisms of Parental Alienation. Psicologia:

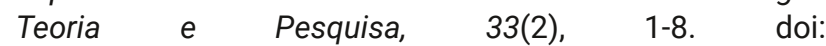
10.1590/0102.3772e33423

Mendes, J. A. A., \& Ormerod, T. (2019). The Best Interests of the Child: An Integrative Review of English and Portuguese literatures. Estudos em Psicologia, 24, 1-22. doi: 10.4025/ psicolestud.v24i0.45021

Mendes, J. A. A., Bucher-Maluschke, J. S. N. F, Vasconcelos, D. F., de Souza, G. G., \& Costa, P. V. M. N. (2016). Perspectiva Sistêmica: um olhar necessário para atuação dos atores jurídicos junto à disputa de guarda. Nova Perspectiva Sistêmica, 25(54), 88-104.

Moraes, M. L. Q. (2014). O sistema judicial brasileiro e a definição do melhor interesse da criança. Estudos de Sociologia, 19(36), 21-39

Nevondwe, L., Odeku, K., \& Raligilia, K. (2016). Reflection on the Principle of Best Interests of the Child: An Analysis of Parental Responsibilities in Custodial Disputes in the South African law. Bangladesh Sociological Society, 13(1), 101114.
Paes, A. M. P., \& Amin, H. C. (2010). A afirmação de novos paradigmas na ciência jurídica a partir de uma visão sistêmica. Trabalho apresentado nos Anais do XIX Encontro Nacional do CONPEDI. Fortaleza/CE, 2010. Disponível em: <http://www.conpedi.org.br/manaus/ arquivos/anais/fortaleza/3651.pdf> Acesso em: 10 set 2016.

Petersen, L. L., \& Figueiredo, C. L. (2011). A constitucionalização do direito de família e o atendimento ao melhor interesse da criança na guarda compartilhada. Revista Direito e sociedade: reflexões contemporâneas, 2(2), 11-34.

Pomerance, B. (2013). Not Just Child's Play: Why Recognizing Fundamental Principles of the UN Convention on the Rights of the Child as Jus Cogens Would Give Needed Power to an Important International Document. Gonzaga Journal of Internationa Law, 16(2), 22-50.

Ribeiro, M. L. (2002). A psicologia jurídica nos juízos que tratam do direito de família no tribunal de justiça do distrito federal. In: Brito, L. M. T. (Org). Temas de psicologia jurídica. Rio de Janeiro: Relume Dumará.

Ribeiro, R. (2010). A criança e o adolescente nos estudos psicossociais de varas de família. In: Ghesti-Galvão, I., \& Roque, E. C. B. (Org.). Aplicação da Lei em Uma Perspectiva Interprofissional: Direito, Psicologia, Psiquiatria, Serviço Social e Ciências Sociais na Prática Jurisdicional. Brasília DF: Lumen Juris.

Santos, D. C. S., \& Fonseca, M. A. M. (2003). A regulamentação de visitas e a dificuldade de separação dos casais. In: Lima, H. G. D. (Org.). Construindo caminhos para a intervenção psicossocial no contexto da justiça. Brasília, DF: TJDFT.

Seger, J. D. S., \& Steinmetz, W. (2015). Direito à autodeterminação sexual e princípio do melhor interesse da criança: a relativização da presunção de violência em crimes sexuais contra menores de quatorze anos. Revista Direitos Fundamentais \& Democracia, 18(18), 275-291.

Silva, C. T. L. (2016). Ensaio Sobre a Possibilidade Jurídica da Guarda Alternada. Revista ESMAT, 5(5), 241-286.

Sormunen, M. (2016). 'In All Actions Concerning Children'?. The International Journal of Children's Rights, 24(1), 155184. doi: $10.1163 / 15718182-02401006$

Souza, J. T. P., \& Miranda, V. R. (2009). Dissolução da conjugalidade e guarda compartilhada. In: Carvalho, M. C. N., \& Miranda, V. C. (Orgs). Psicologia jurídica: temas de aplicação. Curitiba: Juruá Editora.

Sund, L. G., \& Vackermo, M. (2015). The Interest Theory, Children's Rights and Social Authorities. The International Journal of Children's Rights, 23(4), 752-768. doi: 10.1163/15718182-02304002

Unicef. (1989). A Convenção sobre os Direitos da Criança. Nações Unidas. 


\section{W'INTERACÃO EM \\ ET. PSICOLOGIA}

Zawati, M. H., Parry, D., \& Knoppers, B. M. (2014). The best interests of the child and the return of results in genetic research: international comparative perspectives. BMC medical ethics, 72(15), 1-13. doi: 10.1186/1472-6939-1572
Zermatten, J. (2010). The best interests of the child principle: Literal analysis and function. The International Journal of Children's Rights, 18(4), 483-499. doi: $10.1163 / 157181810 \times 537391$

Data de submissão: 22/02/2018 Primeira decisão editorial: 05/03/2018 Aceite em 05/11/2018 